\title{
Hair casts (pseudonits)
}

\author{
Ricardo Ruiz-Villaverde MD PhD, Manuel Galán-Gutierrez MD PhD
}

A 9-year-old girl was referred to our dermatology clinic for an assessment of whitish granules attached to her hair. She was otherwise healthy and had no history of pruritis of the scalp. Her parents had noticed the granules 8 months previously, and she had already received antiscabetic and antifungal treatments (3 weekly courses of $1.5 \%$ permetrin lotion, and daily ketoconazole shampoo for $2 \mathrm{mo}$ ). On physical exami-

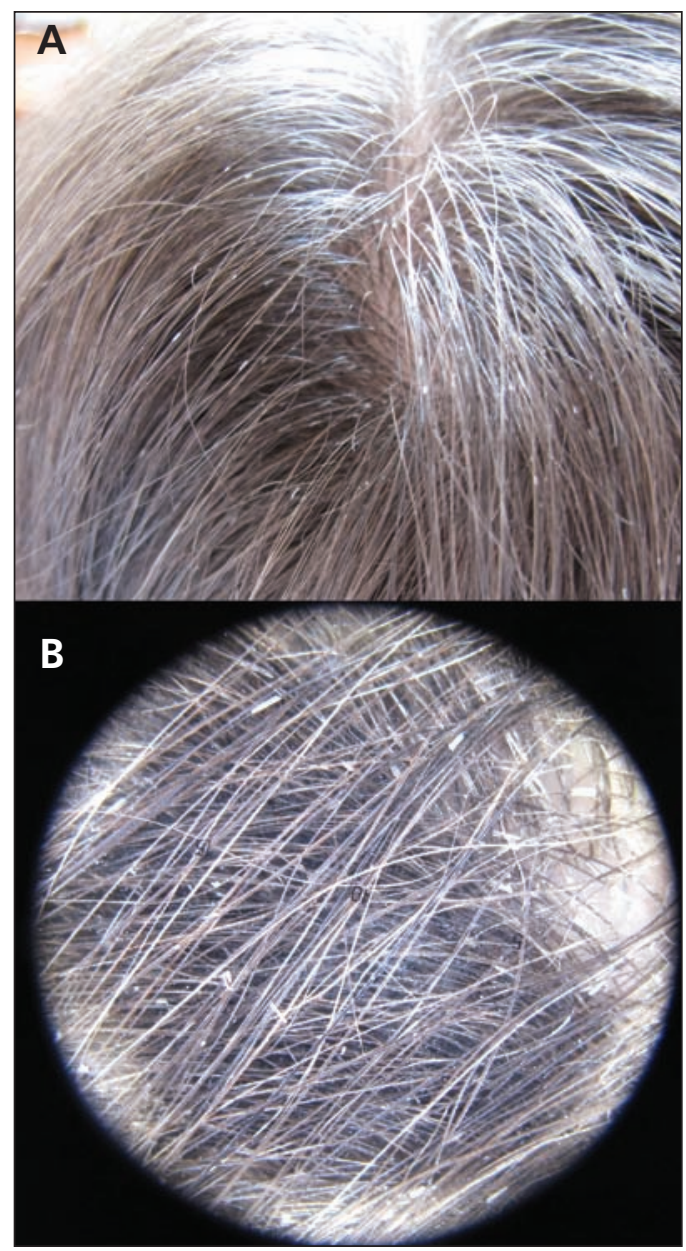

Figure 1: (A) White structures, mimicking nits, enveloping the hair shafts of a 9-year-old girl. (B) Polarized dermoscopy showing whitish-yellow tubular structures with variable lengths encircling the hair shaft in occipital areas of the patient's scalp. nation, we found easily sliding, whitish structures encircling the shafts of the patient's hair (Figure $1 \mathrm{~A}$ and $1 \mathrm{~B}$ ). She did not have alopecia, and her scalp was not inflamed. A full inspection of the patient's skin was normal. We diagnosed pseudonits and prescribed a keratolytic lotion of 3\% salicylic acid. In addition, we recommended using a thin-tooth comb and avoiding traction movements when combing the hair. At a 2-month follow-up, the pseudonits had resolved almost completely.

Peripillous sheaths, also called pseudonits or hair casts, are white-to-yellow tubular structures that encircle the proximal hair shafts of the scalp. Varying in length (2-7 mm), pseudonits slide easily along the shaft without breaking it. ${ }^{1}$ Pseudonits consist of keratinized cells from both the internal and the external epithelial sheaths of the hair root. They are classified as primary when there is no associated scalp condition, and as secondary when associated with scaling scalp conditions such as seborrheic dermatitis and psoriasis. ${ }^{2.3}$ The differential diagnosis includes dandruff, white piedra, trichorrehexis nodosa, monilethrix, trichomycosis and trichonodosis.

Pseudonits can be differentiated from nits by an absence of pruritis and by their mobility along the hair shaft - nits do not slide. If available, dermoscopic examination will show the tubular shape of pseudonits, which helps differentiate them from nits, which are oval. ${ }^{4,5}$ In addition to physical removal, keratolytic lotions or shampoos are helpful. França and colleagues ${ }^{1}$ have described resolution with a solution of $0.025 \%$ retinoic acid, and we have seen good results with a $3 \%$ salicylate lotion; both of these agents are keratolytics.

\section{References}

1. França K, Villa RT, Silva IR, et al. Hair casts or pseudonits. Int J Trichology 2011;3:121-2.

2. Taïeb A, Surleve-Bazeille JE, Maleville J. Hair casts. A clinical and morphologic study. Arch Dermatol 1985;121:1009-13.

3. Ena P, Mazzarello V, Chiarolini F. Hair casts due to a deodorant spray. Australas J Dermatol 2005;46:274-7.

4. Tosti A, Miteva M, Torres F, et al. Hair casts are a dermoscopic clue for the diagnosis of traction alopecia. Br J Dermatol 2010;163:1353-5.

5. Wallace MP, de Berker DA. Hair diagnoses and signs: the use of dermatoscopy. Clin Exp Dermatol 2010;35:41-6.
Competing interests: None declared.

This article has been peer reviewed.

\section{Affiliation: From the}

Department of

Dermatology, Unidad de

Dermatología. Complejo

Hospitalario de Jaén, Jaén,

Spain

Correspondence to:

Ricardo Ruiz-Villaverde, ismenios@hotmail.com

CMAJ 2013. DOI:10.1503 /cmaj.120894 